\title{
Urea Fertilizer for Bangladesh -Challenges and Opportunity
}

\author{
Shafi Ahmed \\ Department of Chemical Engineering, \\ Bangladesh University of Engineering \& Technology (BUET), Dhaka-1000, Bangladesh
}

\begin{abstract}
The outlook for Urea Fertilizer - at present and in coming years for Bangladesh-is a very much concerned issue and studied in the paper. The urea production vs. design capacity of all Fertilizer Plants and consumption has been shown. Main constraint for reduced urea production is identified as Natural gas shortage. To meet countries demand, the possibility of import from global urea supply and its impact on economy is also studied. Analyzing all the above; support to Urea Fertilizer factories- to ensure food security of the country - has been emphasized. Daily Natural Gas requirement for maintaining urea production is estimated.
\end{abstract}

Keywords

Global Urea supply; Food security.

\section{Introduction}

The outlook for Urea Fertilizer - at present and in coming years for Bangladesh-is a very much apprehensive issue that is studied in this paper. About 350 MMSCFD natural gas is required for the yearly production of about 3 million metric ton Urea .This is about $17 \%$ of today's daily gas production of the Country. Ensuring guarantee gas supply and improving the Plant Reliability; Bangladesh total requirement of Urea could be achieved.

Table-1: Consumption and Import of urea Fertilizer

\begin{tabular}{|c|c|c|}
\hline $\begin{array}{c}\text { Financial } \\
\text { Year }\end{array}$ & Import in MT & $\begin{array}{c}\text { Total } \\
\text { consumption }\end{array}$ \\
\hline $2005-06$ & 771,521 & $2,451,375$ \\
\hline $2006-07$ & 651,972 & $2,527,795$ \\
\hline $2007-08$ & $1,162,823$ & $2,762,783$ \\
\hline $2008-09$ & $1,440,341$ & $2,532,966$ \\
\hline $2009-10$ & $1,465,582$ & $2,408,000$ \\
\hline $2010-11$ & $1,813,671$ & $2,655,044$ \\
\hline
\end{tabular}

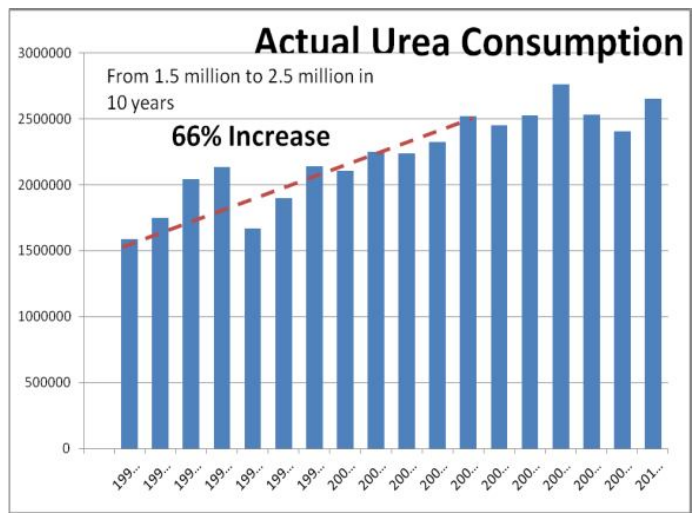

Figure - 1: Consumption of urea in Bangladesh

\section{Production and Supply of Urea from Bangladesh Factories}

The design production capacities of all the urea fertilizer factories are shown in Table-2. Actual production of urea over last 16 years -have also been shown in Figure-2. The production is declining mainly because of the shortage of natural gas supply to the plants. On the other hand; Capacity utilization of the plants are also very poor. The Ashuganj Fertilizer and Chemical Company ltd(AFCCL) has no shortage of natural gas . But due to aging; poor reliability of Plant equipment and management; the plant also has low capacity utilization. With low capacity utilization; the gas consumption per metric ton of urea has also gone high. Capacity utilization of BCIC Plants have been shown in Fig-3 and Fig-4.

Table-2: Design Production and gas requirement of all Fertilizer Plants

\begin{tabular}{|l|r|c|c|}
\hline Factory & Capacity & $\begin{array}{l}\text { Commiss } \\
\text { ioned }\end{array}$ & $\begin{array}{l}\text { mmscfd } \\
\text { Gas } \\
\text { Require } \\
\text { ment }\end{array}$ \\
\hline CUFL & 561,000 & 1987 & 50 \\
\hline JFCL & 561,000 & 1992 & 50 \\
\hline ZFCL & 528,000 & 1980 & 45 \\
\hline UFFL & 470,000 & 1970 & 45 \\
\hline NGFF & 100,000 & 1958 & 25 \\
\hline PUFF & 95,000 & 1985 & 20 \\
\hline KAFCO & 574,425 & 1994 & 62 \\
\hline Shahjalal & 561,000 & 2014 & 50 \\
\hline Total: & $\mathbf{3 4 , 5 0 4 , 2 5}$ & & $\mathbf{3 4 7}$ \\
\hline
\end{tabular}




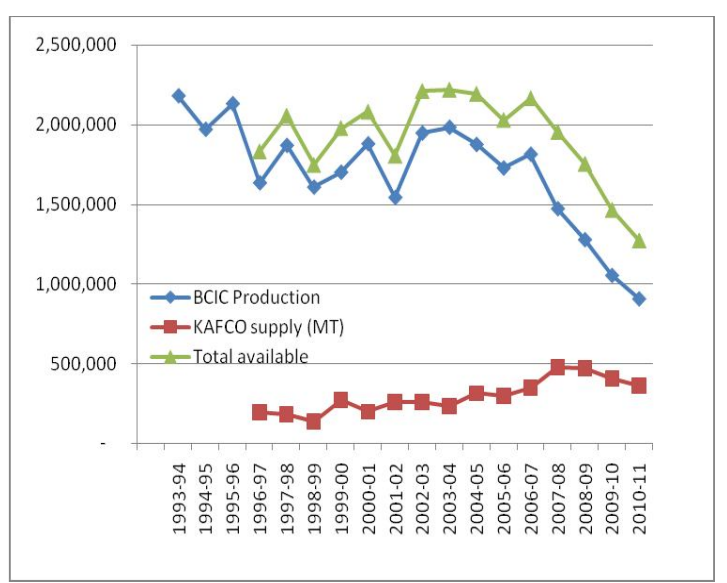

Figure - 2: Total Fertilizer available, MT (BCIC+KAFCO)

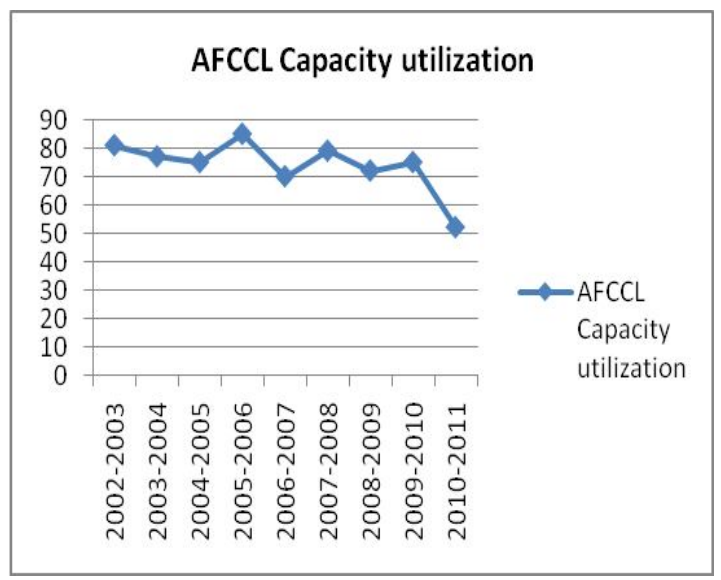

Figure - 3: Capacity utilization; \%-AFCCL Plant

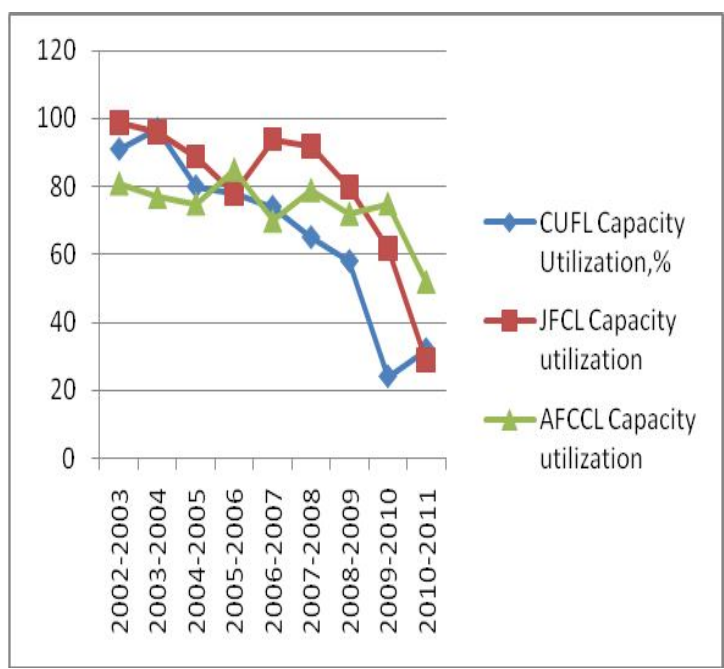

Figure - 4: Capacity Utilization of BCIC Plants, \%

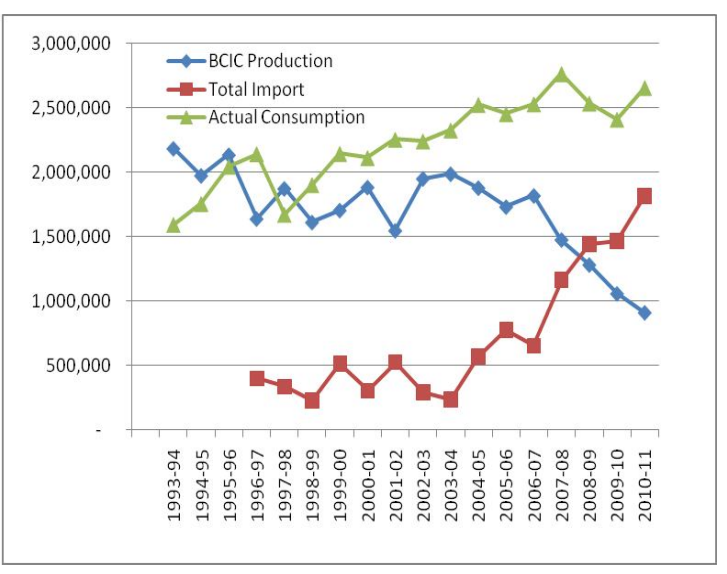

Figure - 5: Capacity Utilization of BCIC Plants, \%

- The Urea fertilizer import is continuously increasing over the last 18 years. Import started first in 1994-95 with about 170,000 MT; and recent years exceeds 1.5 million ton per year

- Main reason of urea import is because of gas has been suspended fully or partly in Fertilizer Plants and poor reliability of Plant.

- With reduced production ; gas utilization has also increased

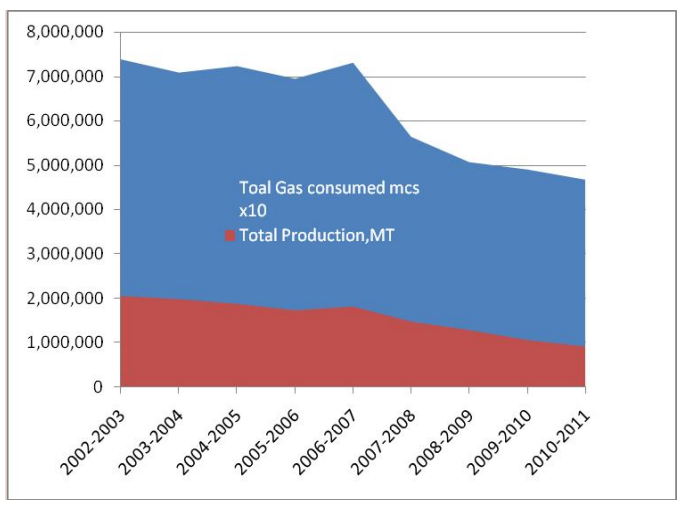

Figure - 6: Reduction of gas does not match the reduction in production

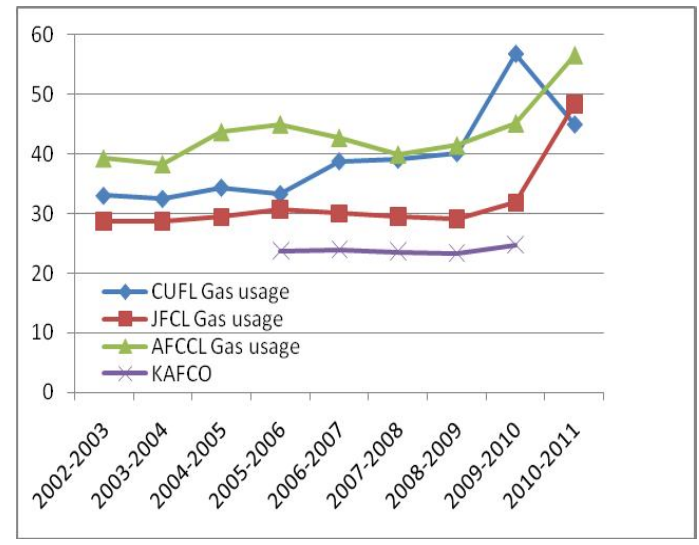

Figure - 7: Gas utilization in BCIC Plants; msf per MT urea 
- Gas Utilization in Bangladesh Fertilizer Plants is very high

- The natural gas consumption in NGFF is the highest - about 2.5 times comparing other Plants

- Gas consumptions is three big capacity Plants ZFCL(AFCCL);CUFL and JFCL are also higher comparing modern Plants

- $\quad$ BCIC Plants and KAFCO have been compared. Because of continuous capital replacement and technological innovations; gas consumption remains much lower in KAFCO

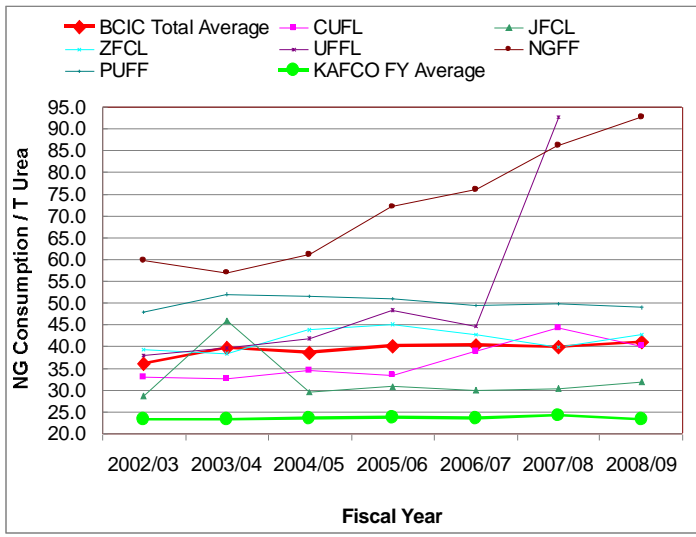

Figure - 8: Gas Utilization in Bangladesh Fertilizer Plants

\section{Urea Global Supply Scenario - Global Fertilizer Consumption}

The global urea supply is very volatile. The forecast is about $4 \%$ increase per anum. The present global consumption is about 150- 175 million metric ton per year. The forecast and consumptions are shown in Fig 9 and Fig 10 by two different estimates.

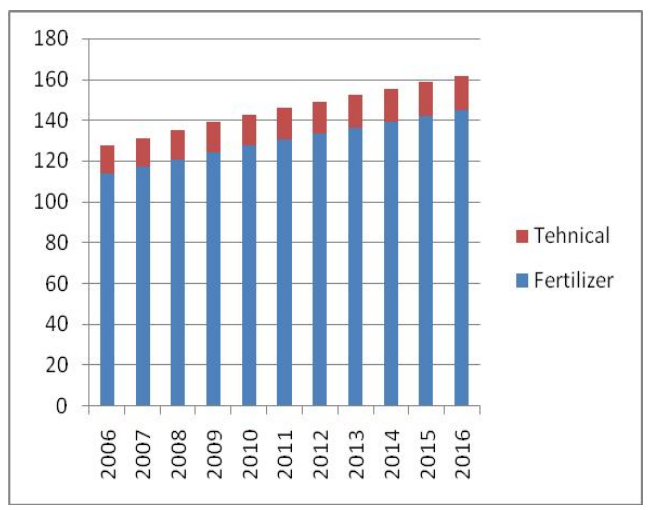

Figure - 9: Global Urea Consumption pattern

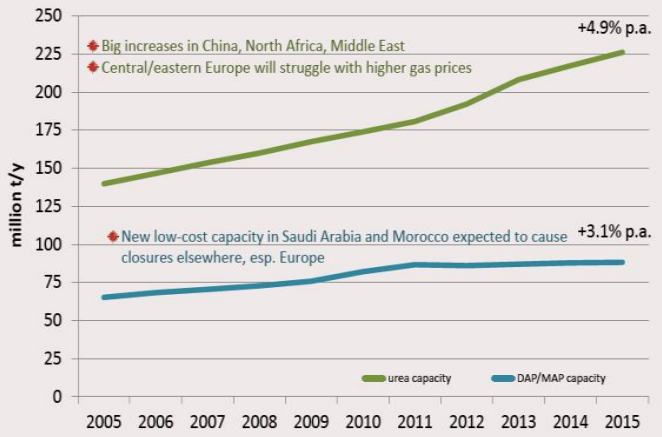

Figure - 10: Forecast- Global Urea Supply

Global urea supplies come from mainly three areas shown in Fig-12.

1. CIS Countries- Ukraine, Russia etc

2. Middle East; including Egypt

3. China

On the other hand; Global Urea importing countries are India, USA, Brazil, Thailand, Pakistan, Bangladesh etc. Ten urea importing countries have been shown in Fig 11; Fig 13 and Fig 14.

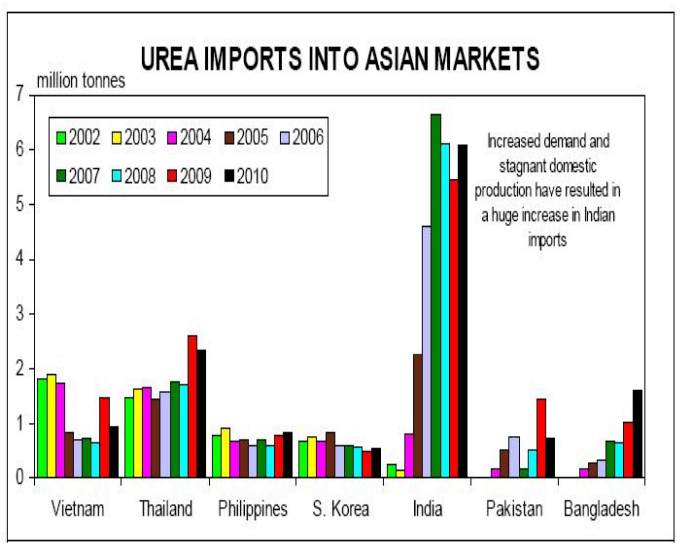

Figure - 11: Urea Imports to Asia

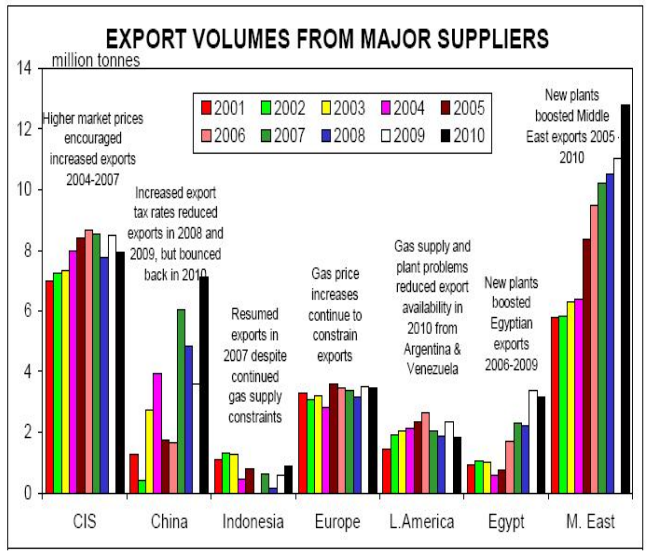

Figure - 12: Major Exporters of Urea 


\section{Top 10 Importers in 2008}

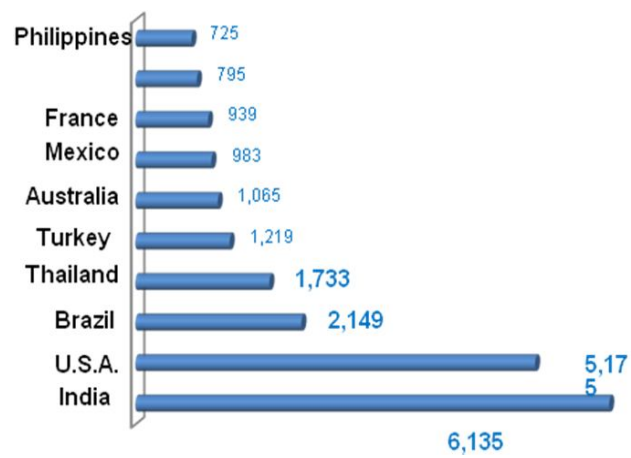

Figure - 13: Ten Importers of Urea -2008

Top 10 Importers in 2018 (forecast)

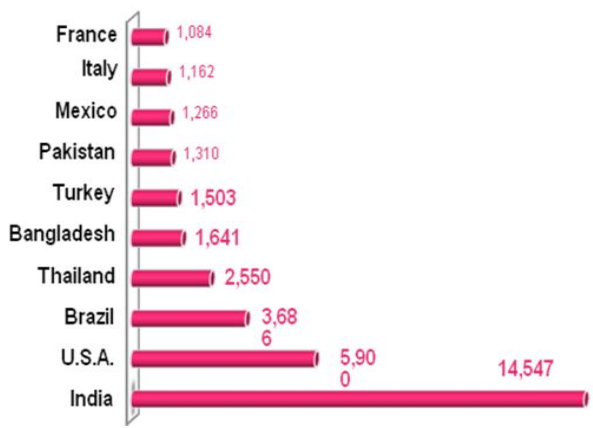

Figure - 1. : Ten Importers in 2018

Bangladesh was not a major urea importing country in 2008; while the forecast says it will be a major urea importing country in 2018.

The challenge of urea import is that India is the biggest urea importer followed by USA. It has a big subsidy on the urea price. Indian import is mainly from middle-east shown in Table-4. When India and USA starts importing; the market volatility becomes high.Table. 3 shows urea import of India.

Table-3: India Urea Fertilizer Import sources

\begin{tabular}{|l|c|c|c|c|}
\hline Country & $2006-07$ & $2007-08$ & $2008-09$ & $2009-10$ \\
\hline Oman & 1.837 & 1.891 & 1.906 & 2.338 \\
\hline KSA & 0.127 & 0.354 & 0.457 & 0.301 \\
\hline Qatar & 0.342 & 0.467 & 0.420 & 0.299 \\
\hline UAE & 0.122 & 0.235 & 0.151 & 0.000 \\
\hline CIS & 1.439 & 0.736 & 1.407 & 0.991 \\
\hline China & 0.154 & 2.635 & 0.496 & 0.534 \\
\hline Others & 0.698 & 0.610 & 0.830 & 0.747 \\
\hline Total & 4.719 & 6.928 & 5.667 & 5.210 \\
\hline
\end{tabular}

Market

2015: FSU / ME biggest exporters; India / NA biggest importers

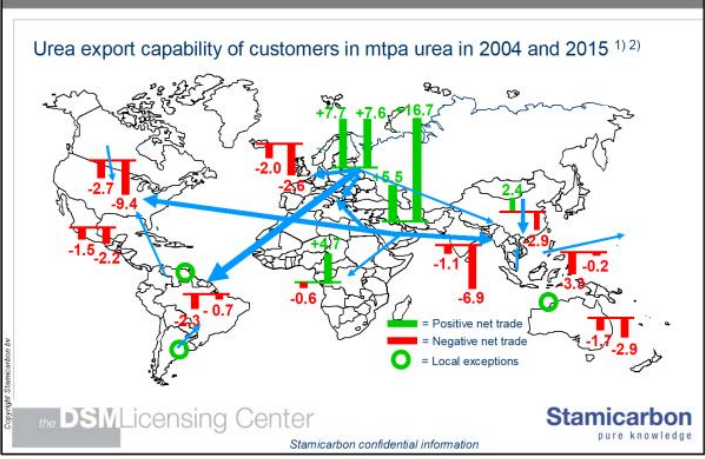

Figure - 2: Global Urea Export Capability

Fig-15 shows the global urea trade: sources and destinations. Middle East countries like Saudi Arabia, Quarter, Kuwait, Oman, Abu-Dhabi, Egypt and Bahrain is the market player. The state of Qatar along will be able to produce 50 million ton urea in near future. Iran having a huge gas reserve is not a market producer and player, because of US embargo on Iranian business.

India has huge shortage of raw material; and cannot produce its requirement. Pakistan is also running shortage of natural gas supply and hence is a net urea importer .Unless the Iranian or Russian gas is allowed to Pakistan or India; both the countries will continue as a major importer.

All East Asian rice producing countries like Thailand; Vietnam, Japan etc are net importers of Urea.

\section{Global Urea Price}

The price of urea is highly fluctuating by historical facts. Many factors play; major role being the energy price fluctuations. The urea market historic price from 1970 to 1980 and the forecasts have been shown in Fig -15 and Fig -16. The highest price was in 2008 in the level of US $\$ 800$ per metric ton .Now, the FOB urea market is over US \$ 500 per metric ton of bulk urea. Adding freight and bag costs; urea cost per ton stands min US \$ 560.

\section{Fertilizer Price-Volatile}

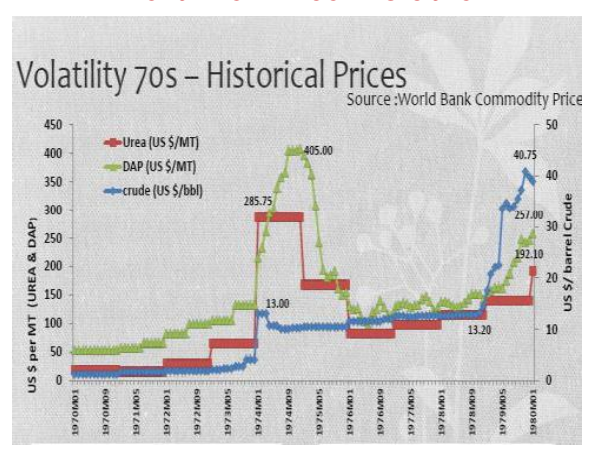

Figure-16: Fertilizer Price-Volatile 


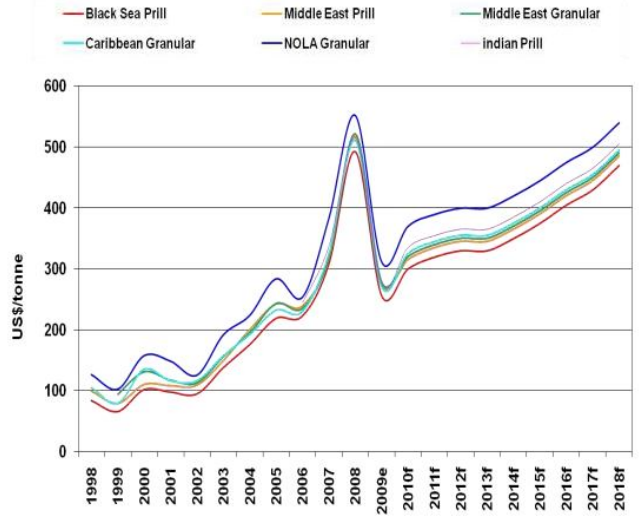

Figure - 3: Actual Urea Price 1999-2011; /ton fob bulk

\section{Cost of Import}

> Bangladesh last year import of 1.5 million ton of urea ; the Gov has to spend about US\$ 840 million equal to Taka 6,600 crore

$>$ If all 2.5 million ton urea has to be imported ; Gov has to spend about 1.4 Billion US \$ equal to Taka 11,000 crore

$>$ In addition to the above; for meeting demand of Phosphate; Sulphur and Potash Fertilizer; another US 600 million; $4700 \mathrm{Cr} \mathrm{Tk}$ is also required.

$>$ Can Bangladesh economy bear this huge cost ; by not producing urea from installed Plants

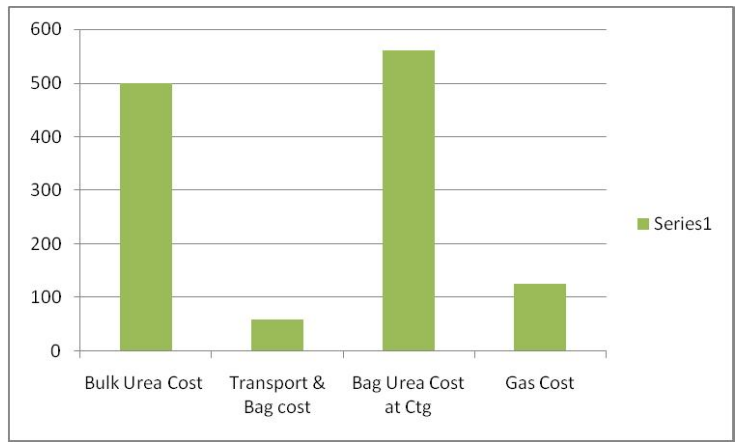

Figure - 4 : Gas Cost is $25 \%$ of Urea Cost

\section{Observations and Recommendations}

$>$ Global supply of Urea is Volatile- very costly and risky to ensure on time

$>$ To continue agricultural production at higher levels and food security, the home UREA production has to be ensured.

$>$ For producing 1.5 million ton yearly; i.e. $4550 \mathrm{mt}$ daily; $136 \mathrm{mmscfd}$ mmscf gas is required [ 30 masc. per ton of urea]

> About equivalent Natural gas is used in Transport. This NG of Transport may be replaced by LPG ; providing the gas to Fertilizer Plants ; as an option

$>$ Present constraint of UREA production (1)Gas supply shortage; (2)Poor Reliability of Plants and (3)High Gas usage
- The concept that Fertilizer can be imported; and electricity not -is economically a very wrong approach. It result huge gas loss and cost huge foreign currency.

- $\quad$ Equivalent energy import is much cheaper - about $25 \%$ of UREA fertilizer import cost

\section{Recommendation}

- Resume full natural gas requirement to all Fertilizer Plants and Reinvest into management improvement and Human resources of the Plant. Establish Programs; Tools and Technologies for improving Plant Reliability; and Reduce gas usage.

- Reserve a portion of our daily gas production for UREA Fertilizer Production.

- Country is now producing over $2000 \mathrm{mmscf}$ Natural gas daily. To meet our UREA requirement fully; about 350 mmscf daily gas will be required. This is $17.5 \%$ of the daily Gas production

- Guaranteeing 350 mmscfd gas for the Urea Plants will help self sufficiency in Urea production and reduce HUGE Import Bill.

\section{References}

Facts and figure presented in this paper is collected from Personal sources; IFA and FERTECON, the special fertilizer journal. It requested not to publish the data of this paper without the permission of the relevant authority. 